\title{
Erlotinib-responsive actinic keratoses
}

\author{
JEAN-FRANCOIS HERMANNS, GERALD E. PIÉRARD and PASCALE QUATRESOOZ \\ Department of Dermatopathology, University Hospital of Liège, Liège, Belgium
}

Received March 6, 2007; Accepted June 4, 2007

\begin{abstract}
Erlotinib is an inhibitor of the tyrosine-kinase domain of the epidermal growth factor receptor-1 (EGFR). This drug is used to treat some solid cancers, particularly advanced non-small-cell lung carcinoma. Similar to other EGFR inhibitors, erlotinib is responsible for a series of skin adverse reactions, particularly acneiform lesions. We described the incidental effect of erlotinib on actinic keratoses which became markedly inflamed and showed partial regression. Inflammation appeared to spontaneously decrease while on erlotinib treatment. This reaction in the skin neoplasm is perhaps a visible and accessible model for predicting the effect in the deep-seated neoplasm targeted by the drug.
\end{abstract}

\section{Introduction}

Erlotinib (Tarceva ${ }^{\circledR}$, Roche Pharma) is a small molecule inhibiting the tyrosine-kinase activity of the EGF receptor (EGFR). The EGFR family is part of a complex signaltransduction network that is central to several critical cellular processes (1). The human EGFR family is disregulated in many solid tumors, making it an attractive target for anticancer therapy. Erlotinib specifically binds to the cytoplasmic domain of the EGFR and has been approved in recent years for chemotherapy-resistant non-small-cell lung carcinoma (NSCLC) (2-6). This drug is also employed for the treatment of a few other solid tumors (7).

Treatments with erlotinib, and other EGFR inhibitors as well, are frequently responsible for cutaneous adverse effects. These unwanted reactions are quite typical for this drug family, and distinct from the skin adverse effects related to other types of anti-cancer chemotherapy (8). The most frequent skin manifestation following anti-EGFR treatment consists of an acneiform pustular eruption (9-11). Other dermatologic reactions include paronychia and some nail changes, abnormalities in hair growth, xerosis, hypersensitivity reactions, non-specific maculopapular rashes, stomatitis, mucositis and pruritus (9-11). One case report described the incidental development of inflammation of

Correspondence to: Professor G.E. Piérard, Department of Dermatopathology, CHU Sart Tilman, B-4000 Liège, Belgium

E-mail: gerald.pierard@ulg.ac.be

Key words: erlotinib, actinic keratoses previously undetected actinic keratoses while on sorafenib therapy (12). We presently report the self-limited inflammatory flare-up of actinic keratoses during erlotinib treatment. To the best of our knowledge, this condition has never been reported as a complication of erlotinib treatment.

\section{Actinic keratoses and squamous cell carcinomas}

Chronically sun-exposed skin of the face is susceptible to develop actinic keratoses which are at risk to evolve into squamous cell carcinomas (13-15). These lesions are increasingly recognized in individuals at the age when internal cancers are also prevalent $(16,17)$.

There are many methods for treating actinic keratoses (18). Physical procedures for destroying the lesions are commonly used. Some specific topical drugs are also employed. Among them, imiquimod and 5-fluorouracil have proven their efficacy (19). Inflammation is typically present during their regression phase $(20,21)$, but also conversely during progression of actinic keratoses to squamous cell carcinomas (22).

Other conventional chemotherapeutic agents which have been associated with the inflammation of actinic keratosis include docetaxel, doxorubicin, capecitabine, pentostatin, sorafenib and the combination of dactinomycin, vincristine, dacarbazine and doxorubicin, cytarabine and 6-thioguanine $(8,12,23,24)$. The mechanism by which these agents lead to this effect is unknown, although abnormal DNA synthesis and a form of radiation recall have been postulated (12).

\section{Erlotinib and actinic keratoses}

The effect of erlotinib on actinic keratoses was first documented as an incidental finding in a 77-year-old man treated for a cisplatin-resistant NSCLC. This phototype 2 patient had also been previously treated for several actinic keratoses and basal cell carcinomas developed on photoexposed areas. The actinic keratoses which were not responsive to topical 5-fluorouracil were destroyed by electrocoagulation. In addition, a total of 28 basal cell carcinomas were surgically excised over a period of years and were submitted for histopathologic confirmation.

Two years ago, the patient was diagnosed with a T2 N1 MO NSCLC and treated by lobar excision and radiotherapy. One year later, abdominal metastases developed. They were first treated with cisplatin chemotherapy without any obvious clinical response. Recently, a therapy of $150 \mathrm{mg}$ /day erlotinib (Tarceva) was initiated. 


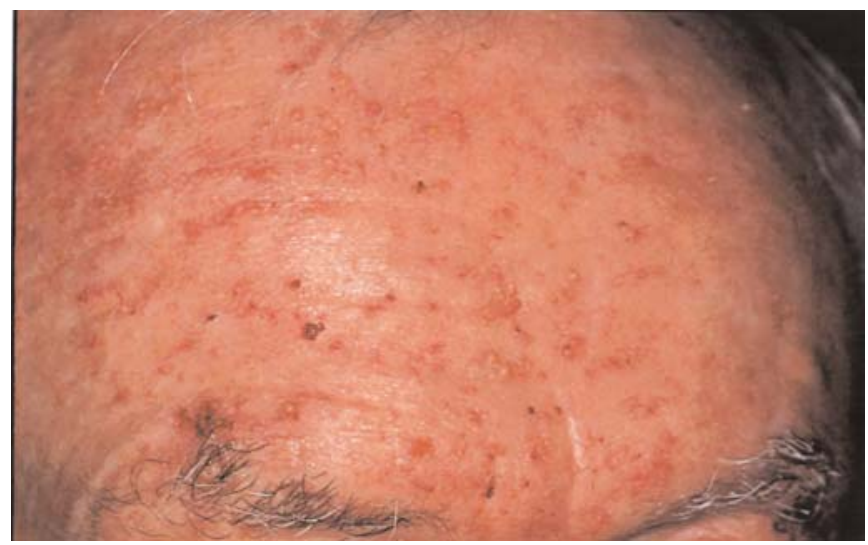

Figure 1. Itchy pustules and patches of serosquamous material on the face at day 10 of erlotinib treatment.

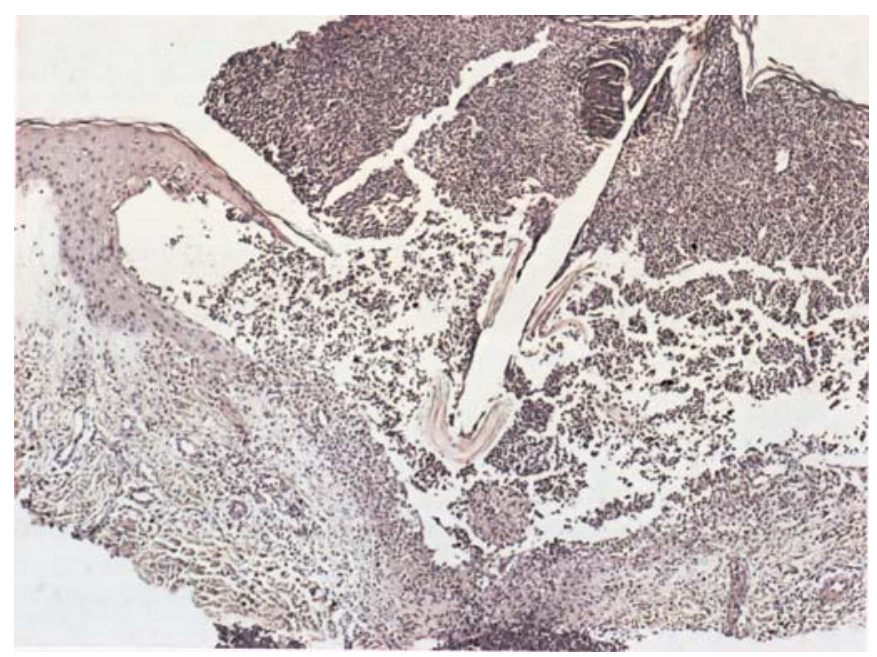

Figure 2. Histological characteristics of a follicular pustule on the face.

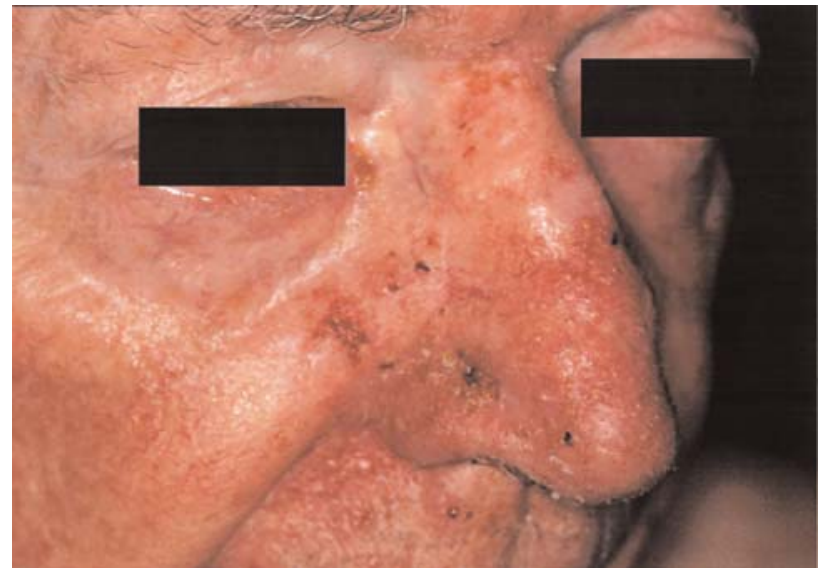

Figure 3. Clinical characteristics of inflammatory changes at the site of the actinic keratoses on day 10 of erlotinib treatment.

At day 10 of erlotinib treatment, itchy pustules appeared on the face, trunk and limbs (Figs. 1 and 2). Crusts formed on the scalp and a xerotic dermatitis developed mainly on the

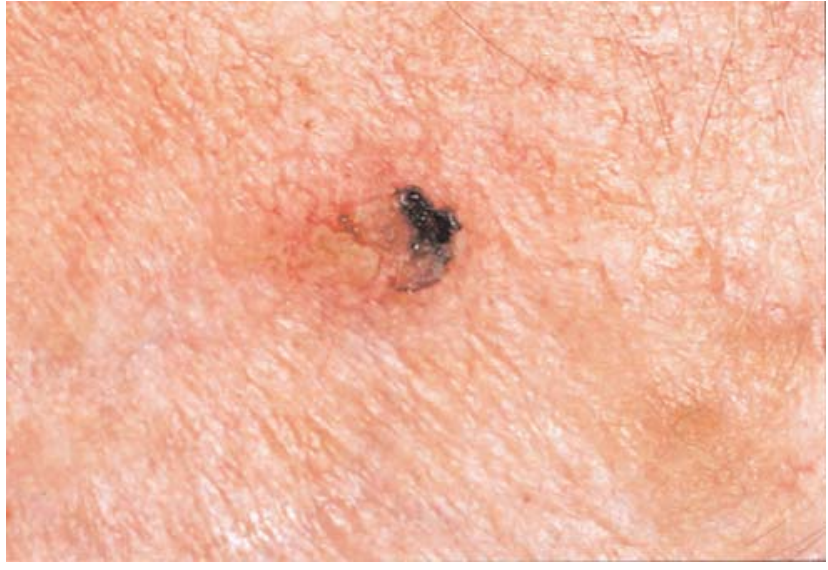

Figure 4. Crust and superficial necrosis of an actinic keratosis.

a

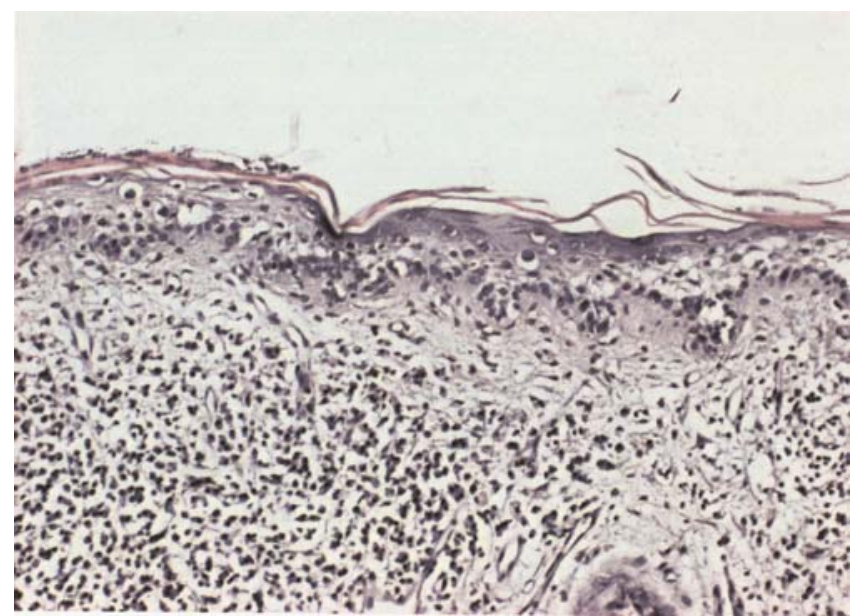

b

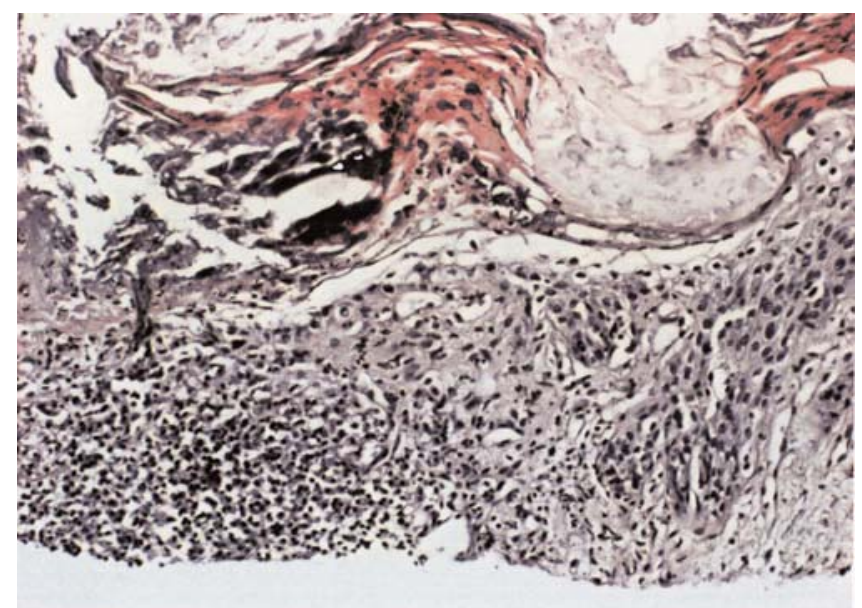

Figure 5. (a) Histological characteristics of actinic keratosis. (b) Neoplastic epithelial dissociation by an intense inflammatory infiltrate with tissue destruction and neoplastic regression.

arms. These manifestations corresponded to the typical adverse effects of erlotinib. They were treated with limecycline, $300 \mathrm{mg} \times 2 /$ day, benzoyl peroxide gel on the face and mometasone furoate solution on the scalp. Treatment with 


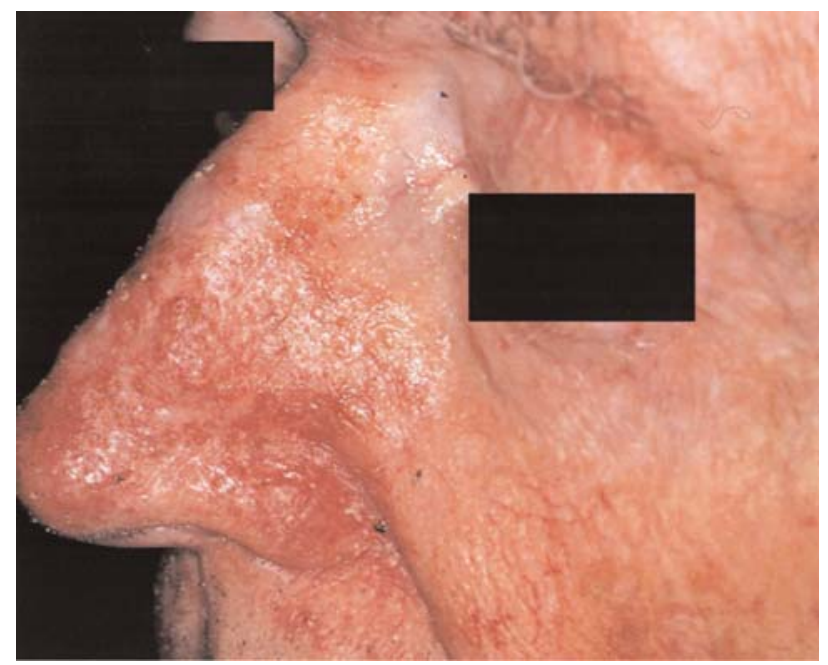

Figure 6. Clinical characteristics of inflammatory actinic keratoses after 2 months of erlotinib treatment.

erlotinib was continued. A marked improvement of the pustular eruption and of the squamous dermatitis of the scalp was observed after approximately three weeks.

Upon examination 10 days after starting erlotinib treatment, inflammatory changes were present at the site of the actinic keratoses on the face (Fig. 3). They led to squame-crust formation underlined by superficial necrosis of the epithelial tumors (Fig. 4). After clearing away the necrotic debris, healing was observed. A biopsy was taken at day 20 of erlotinib treatment. The microscopic examination showed the typical epidermal characteristics of actinic keratosis/in situ squamous cell carcinoma (Fig. 5a). The density of the lymphoid cell infiltrate was quite extensive. The epidermal neoplasm was focally infiltrated and dissociated by the inflammatory cells. At these sites, there were discrete signs of neoplastic regression and partial destruction (Fig. 5b). Two months later, the skin lesions were unchanged (Fig. 6) but the general status of the patient was progressively altered.

Since that initial case of inflammatory actinic keratoses while on erlotinib treatment, a few other cases were observed by our staff members. However, these cases are too few to allow any assessment of the incidence of this condition.

\section{EGFR inhibitors and inflamed actinic keratosis in perspective}

There is a conceptual controversy regarding actinic keratosis as a precursor of, or as an already in situ squamous cell carcinoma $(16,25-27)$. It is also uncertain whether to interpret inflammation of actinic keratosis as a sign of neoplastic progression or regression (22). In any case the severity of the histological grading of the neoplasm is important to consider. Indeed, any inflammatory change in incipient or superficial actinic keratosis is of little importance in the short term because the risk of dermal invasion and distant metastasis is minimal or absent. By contrast, the thicker lesions ready to evolve into a full-blown squamous cell carcinoma are more problematic. Tragically, the few months of survival time expected of the patients undergoing anti-EGFR therapy for a metastatic NSCLC will likely not be affected by any progression of actinic keratoses.

More importantly, the effect of erlotinib on actinic keratoses and in situ squamous cell carcinoma might be regarded as a model in the understanding of the drug's effect on internal carcinomas including NSCLC. The reactions at these skin sites might possibly be better correlated with the efficacy of the drug on the target neoplasm than with any other cutaneous sign $(28,29)$. In this condition, the role of the inflammatory cell infiltrate is probably similar to that of a bystander. Indeed, the drug is expected to exert a primary effect on the neoplastic cells themselves. The inflammatory cell reaction is limited to a secondary reactive process to the neoplastic damages. This condition would therefore be different from the usual immune response mounted against neoplasms and occasionally inducing a partial or total regression.

\section{Conclusion}

We reported an undescribed adverse effect of erlotinib at the site of actinic keratoses. The lesions became inflamed and showed partial regression. We did not encounter a complete clearing of these tumors.

\section{References}

1. Bunn JPA and Franklin W: Epidermal growth factor receptor expression, signal pathway, and inhibitors in non-small cell lung cancer. Semin Oncol 29: 38-44, 2002.

2. Pollack VA, Savage DM, Baker DA, et al: Inhibition of epidermal growth factor receptor-associated tyrosine phosphorylation in human carcinomas with CP-358,774: dynamics of receptor inhibition in situ and antitumor effects in athymic mice. J Pharmacol Exp Ther 291: 739-748, 1999.

3. Pérez-Soler R, Chachoua A, Hammond LA, et al: Determinants of tumor response and survival with erlotinib in patients with non-small-cell lung cancer. J Clin Oncol 22: 3238-3247, 2004.

4. Segaert S, Tabernero J, Chosidow O, Dirschka T, Elsner J, Mancini L, et al: The management of skin reactions in cancer patients receiving epidermal growth factor receptor targeted therapies. J Dtsch Dermatol Ges 3: 599-606, 2005.

5. Shepherd FA, Rodrigues Pereira J, Ciuleanu T, et al: Erlotinib in previously treated non-small-cell lung cancer. N Engl J Med 253: 123-132, 2005.

6. Tang PA, Tsao MS and Moore MJ: A review of erlotinib and its clinical use. Expert Opin Pharmacother 7: 177-193, 2006.

7. Catania C, De Pas TM, Pelosi G, Manzotti M, Adamoli L, Nole $\mathrm{P}$ and Goldhirsch A: Erlotinib-induced breast cancer regression. Ann Pharmacother 40: 2043-2047, 1006.

8. Wyatt JA, Leonard GD and Sachs DL: Cutaneous reactions to chemotherapy and their management. Am J Clin Dermatol 7: 45-63, 2006.

9. Segaert S and Van Cutsem E: Clinical signs, pathophysiology and management of skin toxicity during therapy with epidermal growth factor receptor inhibitors. Ann Oncol 16: 1425-1433, 2005 .

10. Agero AL, Dusza SW, Benvenuto-Andrade C, Busam KJ, Myskowski P and Halpern AC: Dermatologic side effects associated with the epidermal growth factor receptor inhibitors. J Am Acad Dermatol 55: 657-670, 2006.

11. Piérard-Franchimont C, Blaise G, Paquet P, et al: Paroxysmal iatrogenic acne and the epidermal growth factor receptor inhibitors. Rev Med Liège 62: 11-14, 2007.

12. Lacouture ME, Desai A, Soltani K, Petronic-Rosic V, Laumann AE, Ratain MJ and Stadler WM: Inflammation of actinic keratoses subsequent to therapy with sorafenib, a multitargeted tyrosinekinase inhibitor. Clin Exp Dermatol 31: 783-785, 2006.

13. Czarnecki D, Meehan CJ, Bruce F and Culjak G: The majority of cutaneous squamous cell carcinomas arise in actinic keratoses. J Cutan Med Surg 6: 207-209, 2002. 
14. Ehrig T, Cockerell C, Piacquadio D and Dromgoole S: Actinic keratoses and the incidence of occult squamous cell carcinoma: a clinical-histopathologic correlation. Dermatol Surg 32: 1261-1265, 2006.

15. Quaedvlieg PJ, Tirsi E, Thissen MR and Krekels GA: Actinic keratosis: how to differentiate the good from the bad ones? Eur J Dermatol 16: 335-339, 2006.

16. Uhoda I, Quatresooz P, Fumal I, Nikkels AF, Piérard-Franchimont C and Piérard GE: Updating trends in cutaneous cancers in southeast Belgium. Oncol Rep 12: 111-114, 2004.

17. Atkins D, Bang RH, Sternberg MR and Chen SC: Reliable methods to evaluate the burden of actinic keratoses. J Invest Dermatol 126: 591-594, 2006.

18. Jeffes EW and Tang EH: Actinic keratosis. Current treatment options. Am J Clin Dermatol 1: 167-179, 2000.

19. Gupta AK, Davey V and Mcphail H: Evaluation of the effectiveness of imiquimod and 5-fluorouracil for the treatment of actinic keratosis: critical review and meta-analysis of efficacy studies. J Cutan Med Surg 9: 209-214, 2005

20. Quatresooz P and Piérard GE: Imiquimod-responsive basal cell carcinomas and factor XIIIa-enriched dendrocytes. Clin Exp Dermatol 28: S27-S29, 2003.

21. Ooi T, Barnetson RS, Zhuang L, McKane S, Lee JH, Slade HB and Halliday GM: Imiquimod-induced regression of actinic keratosis is associated with infiltration by $\mathrm{T}$ lymphocytes and dendritic cells: a randomized controlled trial. Br J Dermatol 154: 72-78, 2006
22. Berhane T, Halliday GM, Cooke B and Barnetson RS: Inflammation is associated with progression of actinic keratoses to squamous cell carcinomas in humans. Br J Dermatol 146: 810-815, 2002 .

23. Susser WS, Whitaker-Worth DL and Grand-Kels JM: Mucocutaneous reactions to chemotherapy. J Am Acad Dermatol 40: 367-398, 1999

24. Higa GM, Kovach RF and Abraham J: Actinic keratosis and capecitabine therapy. J Oncol Pharm Pract 11: 151-153, 2005.

25. Mittelbronn MA, Mullins DL, Ramos-Caro FA and Flowers FP. Frequency of pre-existing actinic keratosis in cutaneous squamous cell carcinoma. Int J Dermatol 37: 677-681, 1998.

26. Cockerell CJ: Histopathology of incipient intraepidermal squamous cell carcinoma ('actinic keratosis'). J Am Acad Dermatol 42: 11-17, 2000.

27. Hurt MA: The nature of solar (actinic) keratosis. Br J Dermatol 156: 408-409, 2007

28. Perez-Soler R: Can rash associated with HER1/EGFR inhibition be used as a marker of treatment outcome? Oncology 11: 23-28, 2003.

29. Mohamed MK, Ramalingam S, Lin Y, Goodoing W and Belani CP: Skin rash and good performance status predict improved survival with gefitinib in patients with advanced non-small-cell lung cancer. Ann Oncol 16: 780-785, 2005. 